\title{
Are Injuries More Common With CrossFit Training Than Other Forms of Exercise?
}

\author{
Chelsey Klimek, Christopher Ashbeck, Alexander J. Brook, and Chris Durall
}

\begin{abstract}
Clinical Scenario: CrossFit is a form of exercise that incorporates rapid and successive high-intensity ballistic movements. As CrossFit is an increasingly popular fitness option, it is important to determine how rates of injury compare to more traditional forms of exercise. This review was conducted to ascertain the incidence of injury with CrossFit relative to other forms of exercise. Focused Clinical Question: Are injuries more common with CrossFit training than other forms of exercise? Summary of Key Findings: (1) The literature was searched for studies that compared injury rates among individuals who participated in CrossFit fitness programs to participants in other exercise programs. (2) The search initially yielded $>100$ results, which were narrowed down to 3 level $2 b$ retrospective cohort studies that were deemed to have met inclusion/exclusion criteria. (3) In all 3 reviewed studies, the reported incidences of injuries associated with CrossFit training programs were comparable or lower than rates of injury in Olympic weightlifting, distance running, track and field, rugby, or gymnastics. Clinical Bottom Line: Current evidence suggests that the injury risk from CrossFit training is comparable to Olympic weightlifting, distance running, track and field, rugby, football, ice hockey, soccer, or gymnastics. Injuries to the shoulder(s) appear to be somewhat common with CrossFit. However, the certitude of these conclusions is questionable given the lack of randomization, control, or uniform training in the reviewed studies. Clinicians should be aware that injury is more prevalent in cases where supervision is not always available to athletes. This is more often the case for male participants who may not actively seek supervision during CrossFit exercise. Strength of Recommendation: Level $2 \mathrm{~b}$ evidence from 3 retrospective cohort studies indicates that the risk of injury from participation in CrossFit is comparable to or lower than some common forms of exercise or strength training.
\end{abstract}

Keywords: functional training, physical therapy, injury incidence

\section{Search Strategy}

\section{Term Used to Guide Search Strategy}

- Patient/Client group: CrossFit participants

- Intervention/Assessment: CrossFit

- Comparison: running OR weightlifting OR exercise

- Outcome(s): injury OR damage OR trauma OR incidence

\section{Sources of Evidence Searched}

- PubMed

- CINAHL Plus

- SPORTDiscus

- MEDLINE

- EBSCOhost

- Cochrane Database of Systematic Reviews

- Cochrane Central Register of Controlled Trials

- Academic Search Complete

- Academic Search Premier

- Additional resources obtained via manual search of reference lists and suggested articles via searched databases

Klimek, Ashbeck, and Brook are with Physical Therapy Program, University of Wisconsin-La Crosse, La Crosse, WI, USA. Durall is with Physical Therapy Unit, Student Health Center, University of Wisconsin-La Crosse, La Crosse, WI, USA. Durall (cdurall@uwlax.edu) is corresponding author.

\section{Inclusion and Exclusion Criteria}

\section{Inclusion}

- Studies that compared injury rates in CrossFit training to other types of exercise

- Limited to the English language

- Limited to humans

- Limited to the last 10 years (2006-2015)

\section{Exclusion}

- Studies that did not provide data on injury incidence

\section{Results of Search}

Three studies met eligibility requirements and were selected for review. These articles are summarized in Table 1. All 3 studies were survey-based and directly compared rates of injury from participation in CrossFit programs with other fitness programs, such as Olympic weightlifting, running, and gymnastics.

\section{Best Evidence}

The studies in Table 2 were identified as the best evidence for this review. These 3 retrospective cohort studies were classified as level $2 \mathrm{~b}$ evidence based on the Center for Evidence-Based Medicine (CEBM, 2009) criteria. $^{1}$ 


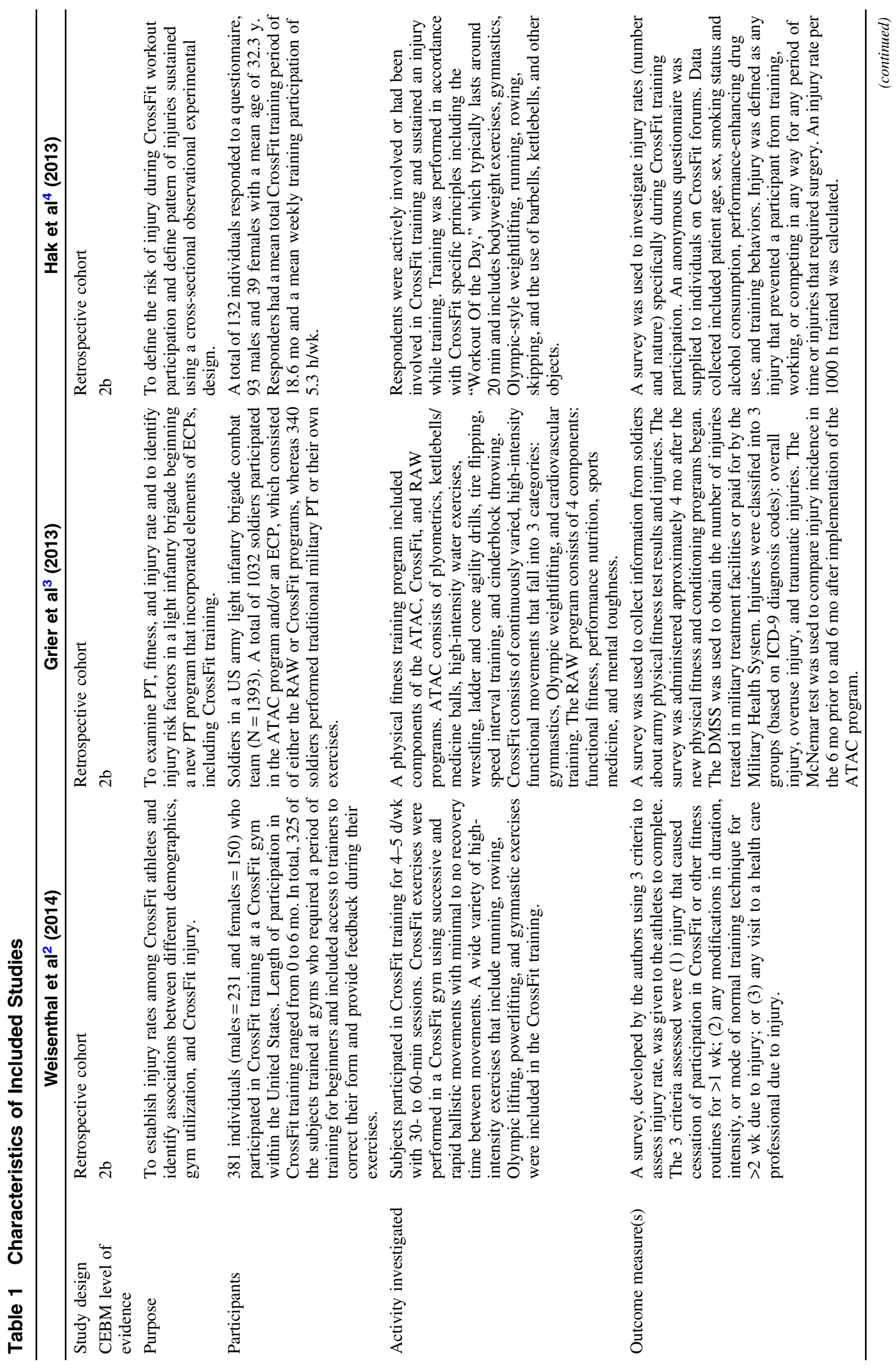




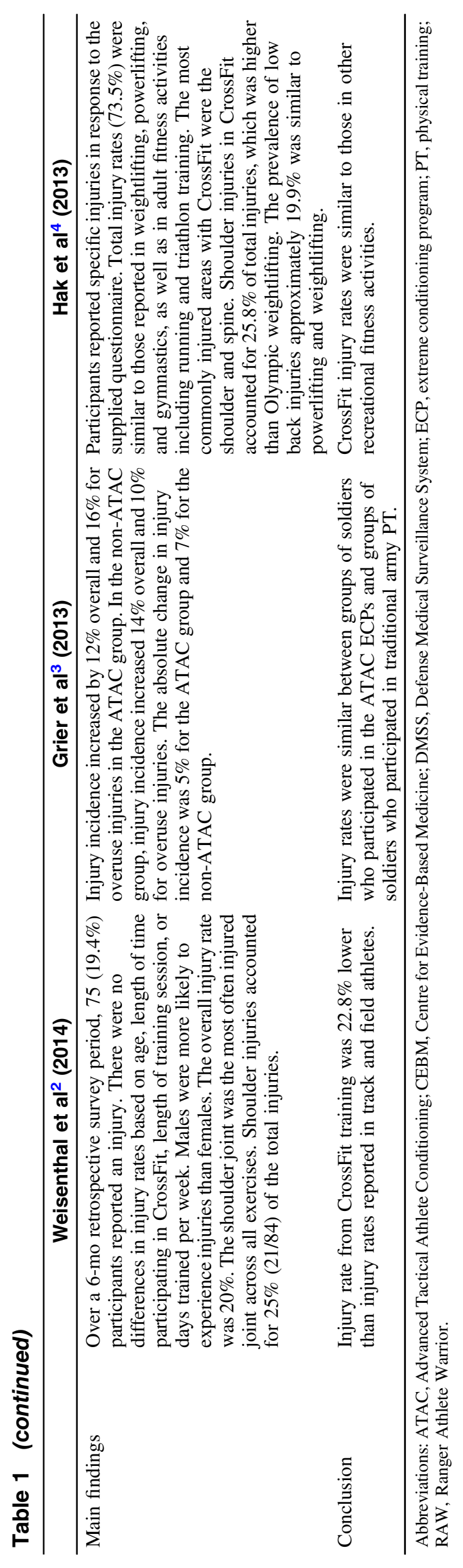


Table 2 Summary of Study Designs of Retrieved Articles

\begin{tabular}{llcl}
\hline $\begin{array}{l}\text { Level of } \\
\text { evidence }\end{array}$ & $\begin{array}{l}\text { Study design/ } \\
\text { methodology }\end{array}$ & $\begin{array}{l}\text { Number } \\
\text { located }\end{array}$ & Author (year) \\
\hline $2 \mathrm{~b}$ & $\begin{array}{l}\text { Retrospective } \\
\text { cohort study }\end{array}$ & 3 & ${\text { Grier et } \mathrm{al}^{3}(2013)}$ \\
& & $\begin{array}{l}\mathrm{Hak}^{3} \mathrm{al}^{4}(2013) \\
\text { Weisenthal et } \mathrm{al}^{2} \\
(2014)\end{array}$ \\
\hline
\end{tabular}

\section{Implications for Practice, Education, and Future Research}

Although high-intensity interval exercise is not a new concept, the CrossFit model of combining various high-intensity functional movements is a relatively recent fad. CrossFit is an exercise program that utilizes high-intensity functional movements with limited amounts of rest to build strength and endurance using a combination of cardiovascular, weightlifting (Olympic and power), and gymnastic-type exercises. ${ }^{2-4}$ Given the novelty of CrossFit training, there is limited research currently available on injury rates. However, the 3 articles retrieved for this review found that the injury rate with CrossFit was comparable to or lower than injury rates with Olympic weightlifting, distance running, military conditioning, track and field, rugby, or gymnastics. ${ }^{2-4}$ Each article defines injury differently, with Weisenthal et $\mathrm{al}^{2}$ describing it as "musculoskeletal pain, feeling or injury as a result of a CrossFit workout that led to at least one of the following situations: total removal from CrossFit or other physical activity for $>1$ week, modification of normal training duration, intensity or mode for $>2$ weeks or a physical complaint severe enough to require a visit to a health care professional." Grier et $\mathrm{al}^{3}$ concluded that injuries ranged from overuse injuries, traumatic injuries, and overall injury. Overall injuries were defined as the total number of injuries from International Classification of Diseases, Ninth Revision (ICD-9) codes 800-999 and 710-739. ${ }^{3}$ Overuse injuries from repetitive microtraumas (ICD codes 710-739) included injuries, such as stress fractures and reactions, tendinitis, shin splints, and general musculoskeletal pain. ${ }^{3}$ Traumatic injuries were defined as those that resulted from sudden force or forces applied to the body (ICD 800-999). ${ }^{3}$ Finally, Hak et $\mathrm{al}^{4}$ proposed that injury was anything that prevented the individual from training, working, or competing in any way and for any period of time.

Weisenthal et $\mathrm{al}^{2}$ found that the injury rate from CrossFit training was $19.4 \%$ over a 6 -month survey period. This injury incidence is no higher than that found for long-distance runners in a systematic review by van Gent et al. ${ }^{5}$ Those authors found that injury incidence in distance and track and field runners ranged from $19.4 \%$ to $79.3 \%$. The most commonly injured areas reported by Weisenthal et $\mathrm{al}^{2}$ were the shoulder, accounting for $25 \%$ of reported injuries, and the lower back and knee, which were involved in $14.3 \%$ and $13.1 \%$ of injuries, respectively. In contrast to the other 2 main articles reviewed, Weisenthal et $\mathrm{al}^{2}$ surveyed only "athletelevel" CrossFit participants, which the article defined as those individuals actively training in CrossFit-affiliated gyms and having some sort of coaching or supervision available. Athletes who performed "CrossFit" workouts in unsanctioned gyms were not included in the study. Hak et $\mathrm{al}^{4}$ allowed respondents to be considered for data review if they had been involved in CrossFit training for any length of time.
Grier et $\mathrm{al}^{3}$ examined overuse injuries, traumatic injuries, and overall injury rates among a US army brigade combat team that participated in extreme conditioning programs that included elements of CrossFit. Those authors found that injury rates were similar between soldiers who participated in extreme conditioning programs and soldiers who participated in traditional army physical training $(\mathrm{PT}) .^{3}$ The extreme conditioning programs in this article include a number of different exercise programs. Two of these programs were the Advanced Tactical Athlete Conditioning program, which includes the use of plyometrics, kettlebells, agility drills, speed interval training, and cinderblock throwing, and the Ranger Athlete Warrior program, which involves a combination of muscular endurance and heavy resistive exercises, power exercises, endurance training, movement skills training, and hybrid training exercises. Both of these programs are based upon similar principles as CrossFit, such as high-intensity repetitions, cardio, and strength. Occasionally, these programs incorporate actual CrossFit exercises into their workout programs, which make them a valuable comparison. More traditional army PT consists of warm-up and stretching exercises followed by calisthenics, push-ups, sit-ups, some sprint training, and group long-distance running. ${ }^{3}$ Participation in the extreme conditioning program resulted in a $12 \%$ (significant at $P=.02$ ) increase in all types of injuries, whereas soldiers who participated in PT had a $14 \%$ (significant at $P=.05$ ) increase in all types of injuries. ${ }^{3}$ Thus, soldiers who participated in the extreme conditioning programs (ie, CrossFit-like programs) had a decreased risk of injury than those participating in typical exercise programs. The increase in overuse injuries was higher in the extreme conditioning group (16\%; significant at $P=.02$ ) versus the PT-only group (10\%; nonsignificant), although the incidence of traumatic injuries was not different between the training groups. The authors did not perform between-group statistical comparisons.

Hak et $\mathrm{al}^{4}$ found that $73.5 \%$ of 132 survey respondents sustained an injury during CrossFit training. ${ }^{4}$ The total injury rate (3.1/1000 $\mathrm{h}$ trained) sustained during CrossFit training was similar to reported injury rates in Olympic weightlifting (3.3/ $1000 \mathrm{~h}$ trained), ${ }^{6}$ gymnastics $(3.1 / 1000 \mathrm{~h}$ trained $),{ }^{7}$ and rugby $\left(3 / 1000 \mathrm{~h}\right.$ trained). ${ }^{8}$ Sports with higher reported rates of injury than CrossFit include American high school football (140 per 1000 exposure hours), 9,10 ice hockey (78.4 injuries per 1000 exposure hours), ${ }^{11}$ and men's and women's soccer competition (4.22 and 5.21 per 1000 exposure hours, respectively). ${ }^{12}$ The injury rates with CrossFit reported by Hak et al $^{3}$ were markedly higher than those reported by Grier et $\mathrm{al}^{4}$ and Weisenthal et $\mathrm{al}^{2}{ }^{2}$ It is unclear why the injury rate was higher in the Hak et al's ${ }^{4}$ study, although differences in sample size and/or response bias may explain some of the disparity between these studies. Differences in CrossFit experience between the reviewed studies may also explain some of the disparities in injury rates. Weisenthal et $\mathrm{al}^{2}$ surveyed only those claiming to be "athlete-level" CrossFit participants, whereas Grier et $\mathrm{al}^{3}$ surveyed military recruits who may have had more experience with high-intensity training. In contrast, Hak et $\mathrm{al}^{4}$ collected data on active participants of any level of participation in CrossFit. Therefore, the high level of previous training by respondents in the Weisenthal et $\mathrm{al}^{2}$ and Grier et $\mathrm{al}^{3}$ studies could account for the lower injury rates when compared with the Hak et $\mathrm{al}^{4}$ study.

Both Hak et $\mathrm{al}^{4}$ and Weisenthal et $\mathrm{al}^{2}$ reported a high incidence of shoulder injuries ( $31.8 \%$ and $25 \%$, respectively) from CrossFit training. The Olympic-style lifts that are inherent to CrossFit require the shoulders to move beyond their usual physiologic range of motion (eg, kipping pull-up). ${ }^{6}$ Another potential 
contributor to CrossFit-related injuries in general and shoulder injuries in particular is muscular fatigue due to high number of repetitions performed during CrossFit sessions. ${ }^{4}$ Muscular fatigue may have particularly deleterious effects on the glenohumeral joint, as congruency of this joint is dependent on sustained muscular activation. Muscular fatigue may also contribute to loss of proper exercise technique and resultant injury. ${ }^{4}$

Weisenthal et $\mathrm{al}^{2}$ found a significantly higher incidence of CrossFit-related injuries in males versus females $(P=.03)$. Females, however, utilized a CrossFit coach significantly $(P=.02)$ more often than males. ${ }^{2}$ Thus, in this study, it is difficult to determine the influence of gender alone on CrossFit-related injuries. The other reviewed studies did not report injury incidence relative to gender. Nonetheless, it may be advisable for athletes of both genders to utilize a qualified CrossFit coach, particularly when starting out.

Additional research is needed on this topic to further the current knowledge regarding CrossFit injury rates as well as to ascertain the long-term impact of CrossFit-related injuries. ${ }^{2-4}$ Injury surveillance should be conducted on all those who participate in CrossFit, whether it be at a certified gym or another location, to determine the impact that proper training can have on injury incidence. Performing CrossFit training under the supervision of qualified trainers may help to modulate injury risk. ${ }^{2}$

\section{References}

1. Centre for Evidence-Based Medicine. Oxford Centre for Evidencebased Medicine - Levels of Evidence (March 2009). https://www. cebm.net/2009/06/oxford-centre-evidence-based-medicine-levelsevidence-march-2009/. Accessed September 2015.

2. Weisenthal BM, Beck CA, Maloney MD, DeHave KE, Giordano BD. Injury rate and patterns among CrossFit athletes. Am J Sports Med. 2014;2(4):2325967114531177. PubMed doi:10.1177/ 2325967114531177
3. Grier T, Canham-Chervak M, McNulty V, Jones B. Extreme conditioning programs and injury risk in a US army brigade combat team. US Army Med Dep J. 2013;36-47. PubMed

4. Hak PT, Hodzovic E, Hickey B. The nature and prevalence of injury during CrossFit training [published online ahead of print November 22, 2013]. J Strength Cond Res. PubMed doi:10.1519/JSC. 0000000000000318

5. van Gent R, Siem D, van Middelkoop M, van Os A, Bierma-Zeinstra $\mathrm{S}$, Koes B. Incidence and determinants of lower extremity running injuries in long distance runners: a systematic review. Br J Sport Med. 2007;41(8):469-480. PubMed doi:10.1136/bjsm.2006.033548

6. Calhoon G, Fry AC. Injury rates and profiles of elite competitive weightlifters. J Athlet Train. 1999;34(3):232-238. PubMed

7. Kolt G, Kirkby R. Epidemiology of injury in elite and subelite female gymnasts: a comparison of retrospective and prospective findings. $\mathrm{Br}$ J Sports Med. 1999;33(5):312-318. PubMed doi:10.1136/bjsm.33. 5.312

8. Williams S, Trewartha G, Kemp S, Stokes K. A meta-analysis of injuries in senior men's professional rugby union. Sports Med. 2013;43(10):1043-1055. PubMed doi:10.1007/s40279-013-0078-1

9. DeLee JC, Farney WC. Incidence of injury in Texas high school football. Am J Sports Med. 1992;20(5):575-580. PubMed doi:10. 1177/036354659202000515

10. Anderson BL, Hoffman MD, Barton LW. High school football injuries: field conditions and other factors. Wis Med J. 1989;88(10): $28-31$.

11. Lorentzon R, Wedren H, Pietila T. Incidence, nature, and causes of ice hockey injuries: a three-year prospective study of a Swedish elite ice hockey team. Am J Sports Med. 1988;16(4):392-396. PubMed doi:10.1177/036354658801600415

12. Rechel J, Yard E, Comstock R. An epidemiologic comparison of high school sports injuries sustained in practice and competition. $J$ Athlet Train. 2008;43(2):197-204. PubMed doi:10.4085/1062-6050-43.2. 197 